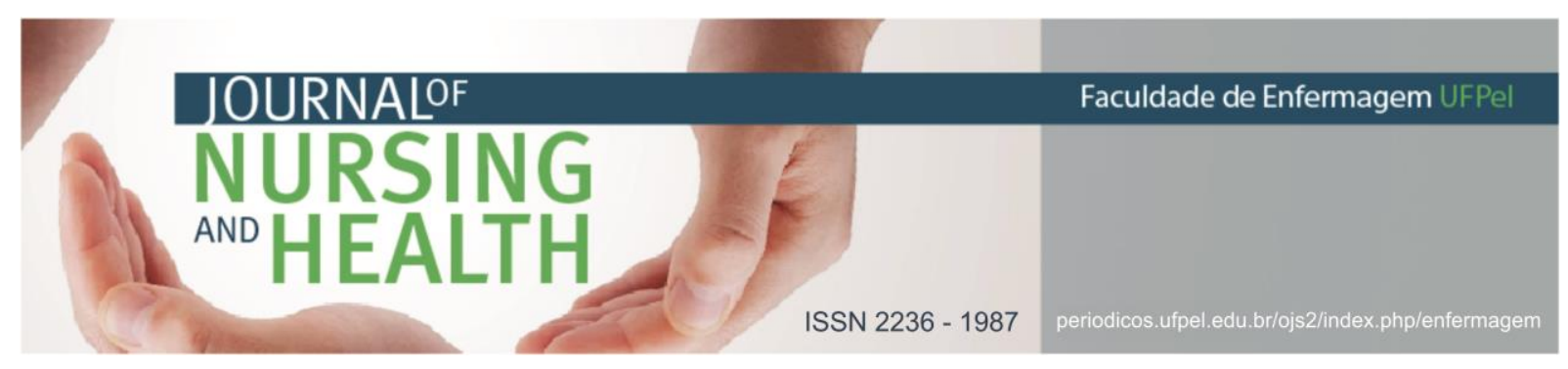

ARTIGO ORIGINAL

\title{
Cuidado à criança com asma: o discurso de familiares
}

\author{
Caring for the child with asthma: relatives' discourse
}

\author{
Atención a los niños con asma: discurso de las familias \\ Silveira, Andressa da ${ }^{1}$; Fávero, Natalia Barrionuevo²; Silva, Júlia Heinz da ${ }^{3}$; Nascimento, Maribel \\ Pereira do ${ }^{4}$; Rodrigues, Daisy Cristina ${ }^{5}$; Neves, Eliane Tatsch ${ }^{6}$
}

\begin{abstract}
RESUMO
Objetivo: descrever os cuidados desenvolvidos pelos familiares à criança com asma. Método: utilizouse o método criativo sensível desenvolvendo-se a dinâmica de criatividade e sensibilidade mapa falante. Os participantes foram familiares/cuidadores de crianças com diagnóstico de asma. Os dados foram submetidos à análise de discurso Pechetiana. Resultados: o cuidado era cotidiano e desenvolvido prioritariamente por mulheres da família, com ênfase na prevenção das crises. As marcas discursivas nas falas das cuidadoras foram: a preocupação, a insegurança e os mitos sobre a doença. Considerações finais: o cotidiano de cuidados dessas crianças é permeado pelo medo de uma nova crise asmática. Como implicação para a prática clínica, sugere-se realizar atividades educativas com as famílias em uma perspectiva emancipatória, promovendo uma aliança de saberes.

Descritores: Saúde da criança; Asma; Cuidadores; Cuidado da criança.
\end{abstract}

\begin{abstract}
Objective: to describe the care developed by relatives to the child with asthma. Method: the sensitive creative method was carried out by developing the dynamics of creativity and sensitivity of the speaking map. Participants were relatives/ caregivers of children diagnosed with asthma. The data were submitted to Pechetiana discourse analysis. Results: care was daily and developed primarily by women in the family, with an emphasis on crisis prevention. The discursive marks in the speeches of caregivers were: the concern, the insecurity and the myths about the disease. Final considerations: the daily care of these children is permeated by the fear of a new asthmatic crisis. As an implication for clinical practice, it is suggested to carry out educational activities with families in an emancipatory perspective, promoting an alliance of knowledge.
\end{abstract}

Descriptors: Child health; Asthma; Caregivers; Child care.

\footnotetext{
${ }^{1}$ Enfermeira. Doutoranda em Enfermagem. Professora Assistente da Universidade Federal do Pampa, Uruguaiana, Rio Grande do Sul, Brasil. E-mail: andressadasilveira@gmail.com

2 Enfermeira. Mestranda em Enfermagem pela Universidade Federal de Santa Maria, Santa Maria, Rio Grande do Sul, Brasil. E-mail: nathybf@hotmail.com

3 Enfermeira. Mestranda em Enfermagem pela Universidade Federal de Santa Maria, Santa Maria, Rio Grande do Sul, Brasil. E-mail: juheinz@hotmail.com.br

${ }^{4}$ Enfermeira graduada pela Universidade Federal do Pampa, Uruguaiana, Rio Grande do Sul, Brasil. E-mail: maribel_pereira89@hotmail.com

${ }^{5}$ Enfermeira. Mestre em Enfermagem pela Universidade Federal de Santa Maria, Santa Maria, Rio Grande do Sul, Brasil. E-mail: daisy_c.r@hotmail.com

${ }^{6}$ Enfermeira. Doutora em Enfermagem. Professora Associada do Departamento de Enfermagem da Universidade Federal de Santa Maria, Professora Permanente do Programa de Pós-graduação em Enfermagem, Santa Maria, Rio Grande do Sul, Brasil. E-mail: elianeves03@gmail.com
} 


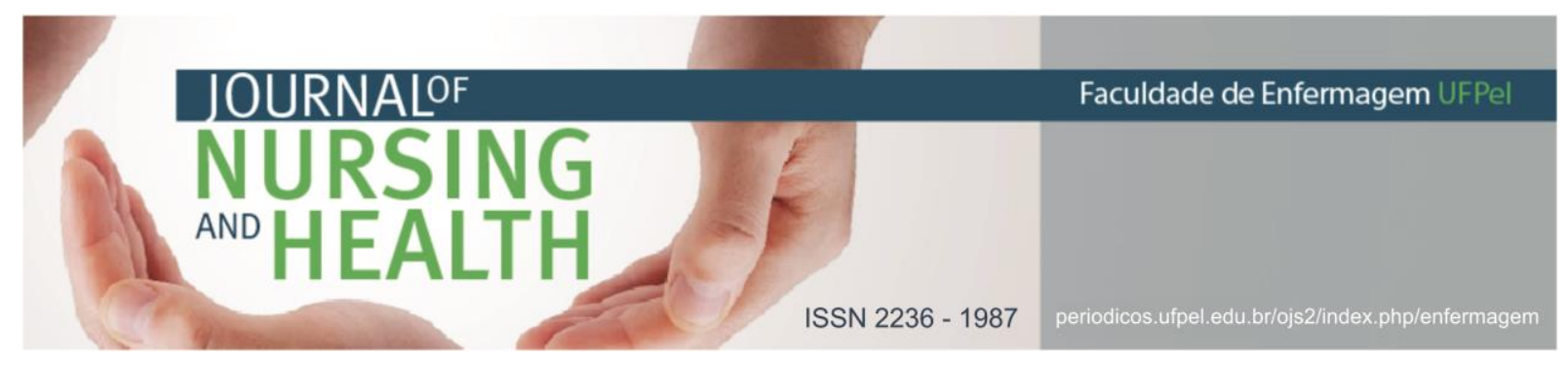

\section{RESUMEN}

Objetivo: describir la atención recibida por los familiares de los niños con asma. Método: se utilizó el método creativo sensible el desarrollo de la dinámica de la creatividad y la sensibilidad mapa altavoz. Los participantes eran familias/ cuidadores de niños con diagnóstico de asma. Los datos fueron sometidos a análisis de discurso Pechetiana. Resultados: cuidado de rutina y fue desarrollado principalmente por las mujeres en la familia, con énfasis en la prevención de crisis. Las marcas discursivas en los informes de los cuidadores fueron: la preocupación, incertidumbre y mitos sobre la enfermedad. Consideraciones finales: el cuidado de estos niños la vida cotidiana está permeado por temor a una nueva crisis de asma. Como se sugiere implicaciones para la práctica clínica llevar a cabo actividades educativas con las familias en una perspectiva emancipatoria, la promoción de una alianza conocimiento.

Descritores: Salud del niño; Asma; Cuidadores; Cuidado del niño.

\section{INTRODUÇÃO}

A asma é a quarta doença mais prevalente em crianças acolhidas nas unidades de saúde do Brasil. Com alta prevalência e impacto na infância, caracteriza-se como um problema de saúde pública, que reflete na economia e qualidade de vida.1-2

Em longo e médio prazo, a asma pode modificar e interferir no desenvolvimento psicossocial, ao restringir a participação em atividades que favorecem as relações sociais, refletindo no desempenho escolar devido ao absenteísmo durante as crises. 2 Ressalta-se ainda, que os fatores de risco acentuam os sintomas da doença, limitando as atividades diárias. 3

Crianças e adolescentes que apresentam demandas de cuidados contínuos, tais como uso ininterrupto de medicamentos, limitações físicas e utilização dos serviços de saúde assiduamente, são classificadas como Crianças com Necessidades Especiais de Saúde (CRIANES)4, pacientes pediátricos com asma estão inseridos neste grupo devido às suas especificidades.
A presença de uma CRIANES modifica o cotidiano e as relações sociais de sua família, que geralmente é quem desenvolve seus cuidados diários. 5 Apesar dos familiares serem identificados como cuidadores principais, ainda são distanciados do planejamento de cuidados pela equipe de saúde. 0 que denota a fragilidade entre o que está previsto na legislação brasileira com a realidade vivenciada por essas famílias. 6

Diante dessas premissas, acredita-se na importância de valorizar - cuidado desenvolvido pelos familiares cuidadores à criança com asma, compreendendo a singularidade da criança e sua família. Frente ao exposto, objetivou-se descrever os cuidados desenvolvidos por familiares/cuidadores à criança com asma.

\section{MATERIAIS E MÉTODOS}

Trata-se de uma pesquisa qualitativa, com abordagem participativa. Desenvolvida a partir do Método Criativo e Sensível (MCS) ${ }^{7}$, com 


\section{NURSING \\ AND \\ HEALTH}

ISSN $2236-1987$

a Dinâmica de Criatividade e Sensibilidade (DCS) mapa falante.

Os participantes do estudo foram quatro integrantes, de duas famílias de crianças com asma, que desenvolviam cuidados domiciliares, assíduos no serviço de saúde, e que utilizassem como referência uma Policlínica Infantil situada na fronteira oeste do sul do Brasil.

Para a seleção dos participantes, foi solicitada a equipe de saúde, a indicação de 10 crianças que utilizassem a Policlínica assiduamente. A partir disso, realizou-se o sorteio aleatório das crianças, classificando-as de um a 10, conforme a ordem do sorteio. Posteriormente, realizou-se contato telefônico com as famílias, a fim de explicar o objetivo da pesquisa, e se aceitassem participar do estudo, uma visita domiciliar seria realizada para o desenvolvimento da dinâmica.

Durante a visita domiciliar, foi solicitado aos participantes que elegessem entre si, o responsável pelos cuidados da criança, sendo eleitas nas duas visitas as mães. Justifica-se um número reduzido de participantes, por se tratar de uma metodologia participativa, que requer domínio da DCS e ainda dos referenciais da análise de discurso. Deste modo, não se faz necessário um corpus abrangente, mas aprofundamento teórico, que pode ser extraído de uma palavra/fala e na profundidade da análise.

A DCS mapa falante caracterizase pela produção artística de um desenho de livre escolha, é possível que $o$ participante apresente a dimensão espacial do cuidado, lugares e pessoas que fazem parte do cotidiano da criança com asma.

A sistematização da DCS ocorreu na residência das famílias, separadamente, mediante a apresentação do objetivo do estudo e da questão disparadora: "Como é o cotidiano do teu filho com asma?"

Para a realização da produção artística, materiais foram disponibilizados (folhas de ofício, canetas hidrocor, lápis de cor, giz de cera). A mãe, eleita como familiar responsável por maior parte dos cuidados da criança, deveria desenvolver a produção artística, e se fosse de sua vontade, poderia solicitar ajuda/participação dos demais membros da família.

Os encontros para a DCS mapa falante foram previamente agendadas por meio de ligação telefônica, as dinâmicas tiveram em média 50-60 minutos. As enunciações foram gravadas em mídia digital, passaram por dupla transcrição e submetidas à análise de discurso Pechetiana. ${ }^{8}$

Após as transcrições, empregouse a materialidade linguística aos discursos, por meio de ferramentas analíticas propostas pela Análise de Discurso como a metáfora, a paráfrase, a polissemia, que mostram como se deu o processo discursivo. ${ }^{8}$ Utilizou-se ainda, recursos ortográficos a fim de dar movimento e melhor compreensão às falas dos participantes.

A pesquisa obteve aprovação pelo Comitê de Etica em Pesquisa com Seres Humanos da Universidade Federal do Pampa, sob número 498.734, e foi conduzida de acordo com os preceitos 


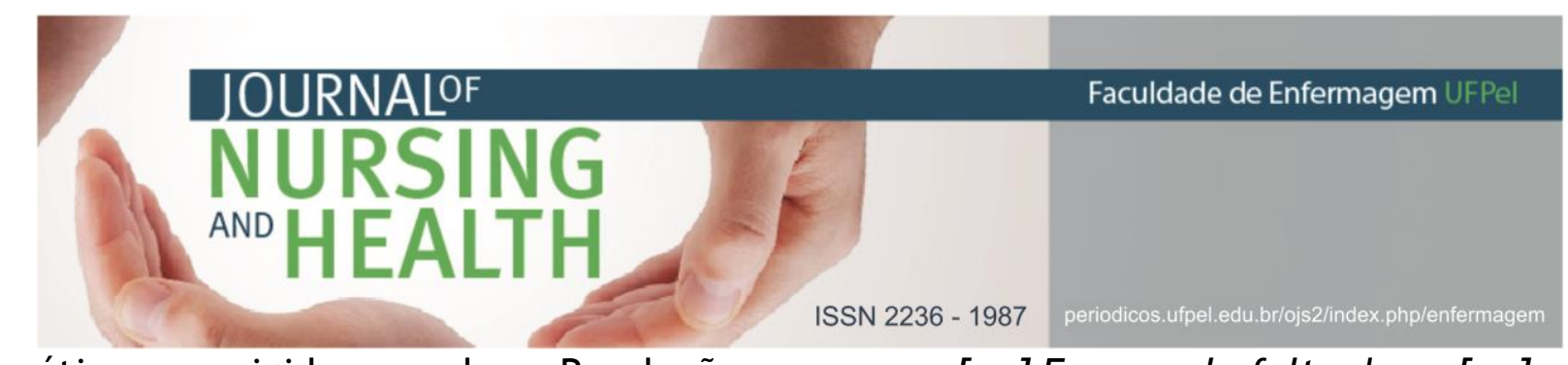

éticos exigidos pela Resolução $466 / 2012 .^{9}$

\section{RESULTADOS E DISCUSSÃO}

Dos quatro participantes do estudo, as famílias elegeram a mãe como principal cuidadora da criança. Essas mulheres caracterizam-se por residirem na fronteira oeste do Rio Grande do Sul e serem mães de criança com asma, o que corrobora com outros estudos em que as mulheres mães assumem o cuidado, muitas vezes solitárias. ${ }^{10}$ Quanto ao estado civil das participantes, uma era casada e a outra possuía união estável.

Com relação à caracterização socioeconômica, as participantes possuíam uma renda de até três salários mínimos. No que diz respeito ao trabalho, ambas trabalhavam fora de casa. Sendo que uma possuía ensino fundamental completo e a outra ensino médio incompleto.

A partir da imersão nas enunciações, emergiram duas categorias: 0 conhecimento e crenças das cuidadoras e as Redes de apoio social no cuidado cotidiano da criança com asma.

\section{O conhecimento e crenças das cuidadoras}

A respeito do conhecimento das cuidadoras sobre a asma, percebeu-se dificuldades em entender a doença, quando notavelmente nos enunciados as participantes comparam bronquite alérgica com asma:

[...] Quando ele era bem pequeno, ele tinha problema de peito, não era assim asma, né?
[...] Era aquela falta de ar [...] o doutor dizia que era bronquite [...] nunca me disse que poderia ser asma [...] mas aí se transformou em asma... (P2).

[...] Ele tava com bronquite, mas era alérgica [...] o doutor não tinha dito que ele tinha asma [...] mas ele não chega a ter uma asma mesmo, né? Ele tem uma crise alérgica [...] (P1).

Clinicamente, a asma e a bronquite têm as mesmas características, a asma se manifesta em forma de crises, com dor no peito, chiado (sibilos), tosse, falta de ar causados pela broncoconstrição. No caso das crises asmáticas, todo esse mal-estar é passageiro e a criança volta ao normal logo que passa essa crise. Já na bronquite, a criança apresenta tosse produtiva crônica, geralmente por mais de três meses durante o ano, por dois ou mais anos consecutivos. Essa grande produção de muco também pode causar broncoconstrição e a dificuldade para respirar, gerando os sintomas parecidos com os da asma. ${ }^{11}$

[...] Tu não sabe o que fazer, tu não sabe nem como socorrer, tu não sabe se assopra ou se abana e não pode abanar porque dizem que é pior [...] $e$ aí fazer o quê? (P1).

Aí foi terrível [...] ele não conseguia acordar, ele revirou os olhos e ficou tipo morto assim... Não conseguia voltar a respirar [...] E ele não respirava, ficou todo molenga (P2).

As cuidadoras mencionaram que, - cotidiano ocasiona situações geradoras de estresse, assim, 
enfatizaram os momentos de medo, insegurança e preocupações acometidas pelas crises asmáticas.

Ao vivenciarem as crises asmáticas dos filhos, protagonizaram momentos de pânico sem saber como agir de imediato, este sentimento foi lembrado de forma negativa. Assim, acredita-se que os enfermeiros, como facilitadores do processo do cuidado às CRIANES, devem tentar reduzir a distância entre o conhecimento científico, e o senso comum, que pertence ao ambiente de mães que prestam cuidados no domicílio. Atuando em prol do auxílio a essas cuidadoras na melhoria da saúde dessas crianças. ${ }^{12}$

A enfermagem é imprescindível no plano de ação preventiva da asma, a partir de atividades de educação em saúde, pois trabalham juntamente às famílias para assegurar uma maior adesão dessas ao tratamento da criança. ${ }^{12-13}$

As crenças e a cultura das cuidadoras influenciam nos cuidados prestados pelas mesmas. Em busca pela cura ou melhora da criança com asma, procuram algo sobrenatural, precisam se apegar a um "ser maior" para que suas angústias, tristezas e a fraqueza sejam aliviadas.

Com o grande (filho mais velho) já fiz bastante simpatias [...] aí tem uma que era do nabo com açúcar mascavo eu fiz! A da flor da bananeira... Do ovo... De pasta com vinho e noz moscada... Mel com limão que era pra fortificar os pulmões $e$ os brônquios, eu fiz! (P1).

Eu vou pra onde o barco me leva (referindo-se a igrejas), se a mãe (avó materna da criança) me convida pra ir na dela (igreja), eu vou! Se a vizinha me convidar, eu vou! (P2).

O discurso das cuidadoras denota a busca incessante de melhorar o convívio com a condição crônica na infância, revela as estratégias de enfrentamento por meio da religião ${ }^{14}$, e até mesmo com os rituais de simpatia. $\mathrm{Na}$ percepção dessas cuidadoras, a religião thes fortalece e as simpatias são estratégias de cuidado.

\section{Redes de apoio social no cuidado} cotidiano da criança com asma

O desenvolvimento da rede social de cuidados da família foi desenhado pelas mães em suas produções artísticas, o que deixou claro nas representações a necessidade de atentar para a importância das relações sociais da criança com asma.

[...] Ele não gostava muito de brincar com ninguém, ficava sozinho, não saía pra lado nenhum. [...] Porque ele não gostava muito de andar correndo na rua, ele tinha um pouco de medo... (a asma afetou as relações sociais da criança) (P1).

Na primeira produção artística, é relatado (Figura 1): 


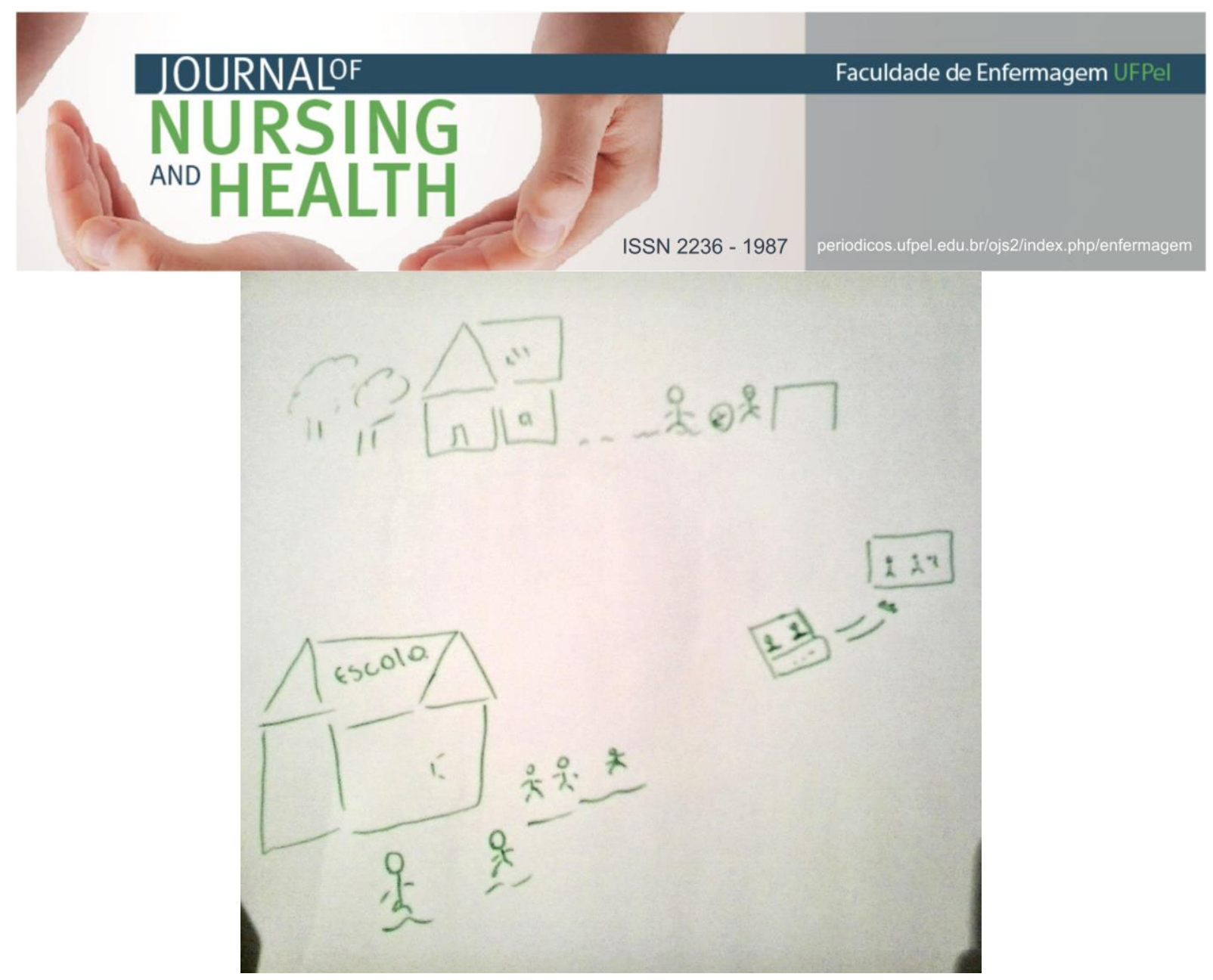

Figura 1 - Produção Artística de P1: Dinâmica Mapa Falante, 2014.

Nota-se que a criança não saía de casa frente ao medo de que desencadeasse uma crise asmática, dificultando suas relações sociais. Contudo, após o tratamento, a criança voltou a conviver com os colegas da escola e com os vizinhos.

O discurso evidencia o sentimento de inferioridade, considerando a asma como uma doença limitadora, uma vez que apresenta situações do cotidiano que revelam fraqueza, as atividades que exigem muito esforço físico impedem que os vínculos sociais sejam fortalecidos. ${ }^{15}$

A fala de $\mathrm{P} 2$ revela o quanto à doença é prejudicial, ao mesmo tempo, denota a aceitação e a necessidade de inclusão da criança, apesar dos desafios que a asma impõe no dia a dia.
É, prejudica bastante, mas tem que aprender a conviver com o que tu tem, né!? (P2).

A asma interfere no cotidiano e nas relações sociais da criança. Essas interferências estão presentes de modo mais intenso ou mais leve, física, emocional e socialmente. ${ }^{15}$ Uma das cuidadoras relata em sua produção artística que a criança, apesar da doença está feliz:

Não sei, aqui (no desenho) ele está feliz! Pra mim, é o que eu acho que importa! Estar feliz e estar bem de saúde... [...] (P2).

Para esta mãe, a estabilidade na condição de saúde de seu filho possibilita conviver com a doença. A normalização e a incorporação da asma na vida das crianças geram segurança para conviver bem com a doença, se todas as medidas de prevenção e promoção da saúde forem tomadas. ${ }^{15}$ 


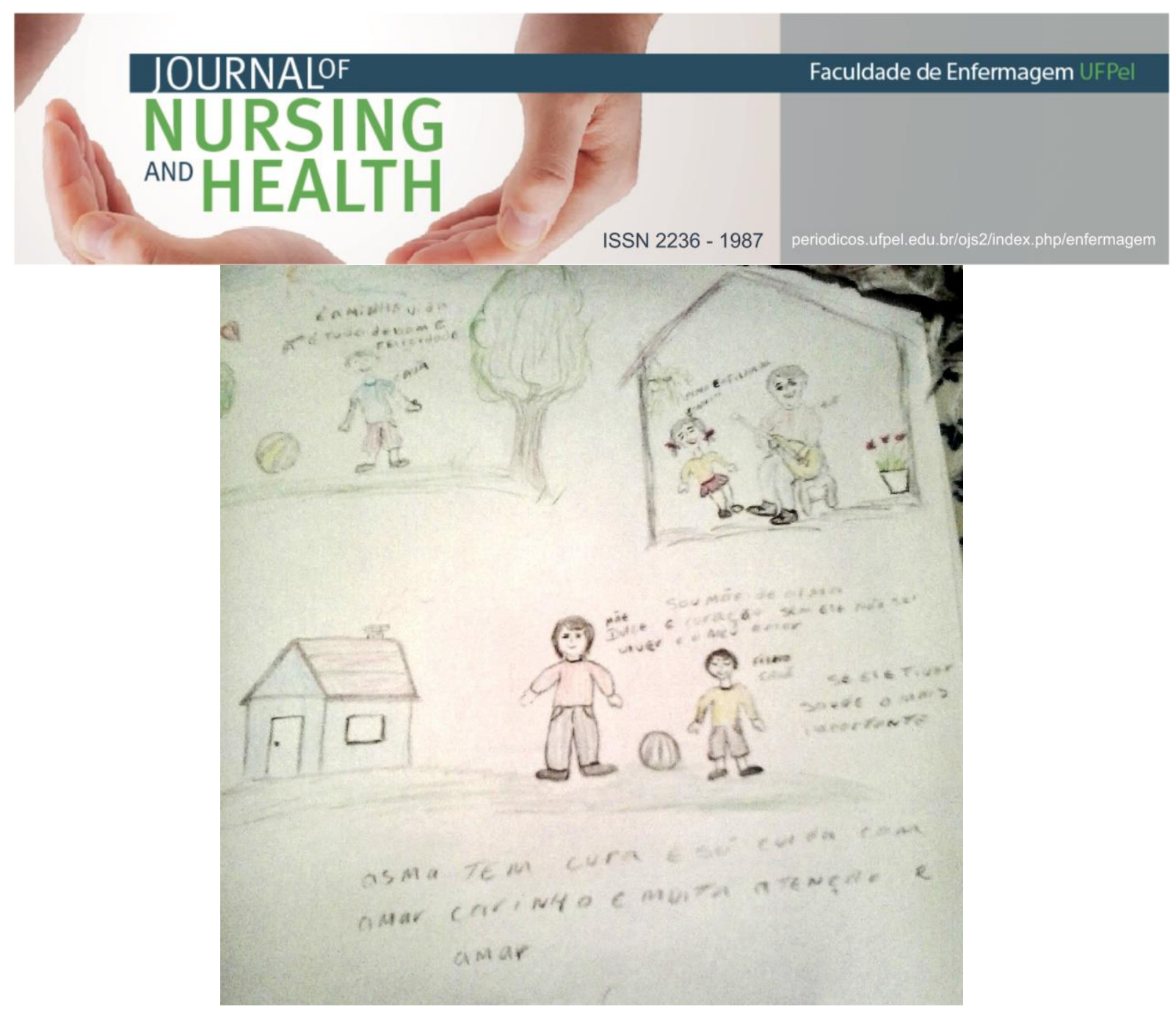

Figura 2 - Produção Artística de P2: Dinâmica Mapa Falante, 2014.

Uma rede social estável, sensível, ativa e protege as crianças de doenças evitáveis, acelera o processo de cura e/ou reabilitação, e aumenta a sobrevida, ou seja, é geradora de saúde. No contexto domiciliar, a articulação da rede de cuidados está centrada nas pessoas da família, que articulam o cuidado familial e o comunitário. ${ }^{16}$

A criança com asma requer dedicação e atenção maior do cuidador principal, podendo ser necessária a modificação de sua rotina para dedicar-se constantemente à criança.

O dia em que ele ficou no hospital foi uma guerra, porque eu deixava a mãe (a avó materna ajudava nos cuidados) lá (no hospital), eu voltava para casa onze e meia, e só dava tempo de eu tomar um banho e fazer alguma coisa pra comer [...] Eu chegava em casa, daqui a pouco tava tocando o telefone (ligação do hospital pedindo para que a mãe retornasse) [...]. Eu que dormia com ele (no hospital) [...] (P2).

O cuidado materno é fundamental no manejo e tratamento, tendo em vista que a infância é uma fase da vida na qual o ser humano não tem total independência para seu autocuidado. ${ }^{17}$

Nem sempre, o cuidado à criança é solitário, às vezes, as mães contam com o envolvimento de outros membros da família:

Todo mundo ajuda, [...] a gente se reveza, porque todo mundo trabalha [...] mas sozinho, 
sozinho, eles (a criança com asma e seu outro filho) não ficam [...] (P1).

Os períodos de crise asmática pode ser um período de dedicação extrema, principalmente, quando há hospitalização. Estudo qualitativo desenvolvido com CRIANES demonstrou que existe um cuidado, muitas vezes solitário, no qual a família compartilha essa responsabilidade apenas com as pessoas mais próximas, como tias e avós. ${ }^{18}$

Apesar das dificuldades cotidianas da criança com asma, é possível identificar o carinho e o comprometimento materno:

Sou mãe de alma e coração, sem ele não sei viver, é o meu amor! Se ele tiver saúde é o mais importante. Asma tem cura, é só cuidar com amor, carinho e muita atenção [...] (P2).

A dimensão do cuidado desenvolvido pelo familiar/cuidador está ligado a sentimentos de amor e carinho da família para com a criança, resgata a responsabilização da família pela sobrevivência da criança e o medo de perdê-la. ${ }^{18}$

A assistência à saúde da criança, assim como a saúde em geral, encontra-se em processo de construção de redes de apoio, em prol da inclusão da família e da integralidade do cuidado, com fuga do modelo biomédico centrado na patologia.

\section{CONSIDERAÇÕES FINAIS}

Concluiu-se que as cuidadoras de crianças com diagnóstico de asma priorizam um cuidado cotidiano de proteção, pois temem novas crises. As
ISSN 2236 - 1987

marcas discursivas em destaque foram: a preocupação, a insegurança e a incerteza presente diariamente no discurso das mães.

O conhecimento das cuidadoras sobre a asma provém de uma série de fatores, entre eles, a crença, a cultura, as tradições que são passadas de geração para geração. Essas mães também acreditam em algo sobrenatural, que faz com que elas não percam as esperanças e prossigam a busca pela cura de seus filhos.

0 cotidiano das crianças com asma é permeado pelo medo de uma nova crise, na prevenção e na privação de algumas atividades do cotidiano, restringindo as relações sociais.

Como implicações para a prática clínica, sugerem-se atividades educativas com as famílias em uma perspectiva emancipatória, promovendo uma aliança de saberes. Com isso, podem-se prevenir crises, contribuir para o empoderamento das cuidadoras e para a qualidade de vida dessas crianças. No que tange às pesquisas, recomenda-se estudos de intervenção com essas famílias e crianças.

\section{REFERÊNCIAS}

1. Solé D, Nunes ICC, Wandalsen GF, Mallozi MC. A asma na criança e no adolescente brasileiro: contribuição do International Study of Asthma and Allergies in Childhood (ISAAC). Rev paul pediatr [Internet]. 2014 [acesso em 2016 nov 12]; 32(1):114-25. Disponível em: http://www.scielo.br/pdf/rpp/v32n1 /pt_0103-0582-rpp-32-01-00114.pdf 


\section{JOURNALOF \\ NURSING \\ ANO HEALTH}

ISSN 2236 - 1987

14];7(5):1458-62. Disponível em: http://www.revista.ufpe.br/revistaen fermagem/index.php/revista/article/ view/3229

7. Soratto J, Pires DE, Cabral IE, Lazzari DD, Witt RR, Sipriano CAS. A maneira criativa e sensível de pesquisar. Rev bras enferm [Internet]. 2014 dez [acesso em 2016 nov 21];67(6):994-9. Disponível em: http: / /www.scielo.br/pdf/reben/v67 n6/0034-7167-reben-67-06-0994.pdf

8. Orlandi EP. Análise do discurso: princípios e procedimentos. $8^{\mathrm{a}}$ ed. Campinas: Ponte Editores; 2013.

9. Ministério da Saúde (BR). Conselho Nacional de Saúde. Resolução 466, de 12 de dezembro de 2012: diretrizes e normas regulamentadoras de pesquisa envolvendo seres humanos. Brasília; 2012.

10. Naitoh Y, Kawauchi A, Soh J, Kamoi $\mathrm{K}$, Miki T. Health related quality of life for monosymptomatic enuretic children and their mothers. J urol [Internet]. 2012 [acesso em 2016 nov 19];188(5):1910-4. Disponível em: https://www.ncbi.nlm.nih.gov/pubm ed/22999692

11. José BP, Camargos PA, Cruz Filho AA, Corrêa RA. Diagnostic accuracy of respiratory diseases in primary health units. Rev assoc med bras [Internet]. 2014 [acesso em 2016 nov 21];60(6):599-612. Disponível em: http: //dx.doi.org/10.1590/18069282.60.06.021

12. Ramos LDC, Moraes JRMM, Silva LF, Goés FGB. Maternal care at home for children with special needs. Invest educ enferm [Internet]. 2015 [acesso em 2016 nov 21];33(3):492-9. Disponível em: 


\section{JOURNALOF \\ NURSING \\ AND HEALTH}

ISSN 2236 - 1987

22];15(2):533-40. Disponível em: https://www.fen.ufg.br/fen_revista/ v15/n2/pdf/v15n2a28.pdf

18. Silveira A, Neves ET, Paula CC. Cuidado familial das crianças com necessidades especiais de saúde: um processo (sobre)natural e de (super)proteção. Texto contexto enferm [Internet]. 2013 [acesso em 2016 nov 22];22(4):1106-14. Disponível em:

http://www.scielo.br/pdf/tce/v22n4/ 29.pdf

Data de submissão: 21/12/2016

Data de aceite: 01/05/2017

Data de publicação: 30/08/2017

a crianças portadoras de doenças crônicas. Texto contexto enferm [Internet]. 2015 [acesso em 2017 maio 13];24(3):662-9 Disponível em: scielo.br/pdf/tce/v24n3/pt_01040707-tce-24-03-00662.pdf

15. Trinca MA, Bicudo IMP, Pelicioni MCF. A interferência da asma no cotidiano das crianças. Rev bras crescimento desenvolv hum [Internet]. 2011 [acesso em 2016 nov 23];21(1):70-84. Disponível em: http: / /www.revistas.usp.br/jhgd/arti cle/view/19997/22083

16. Moraes JRMM, Cabral IE. A rede social de crianças com necessidades especiais de saúde na (in)visibilidade do cuidado de enfermagem. Rev latinoam enfermagem [Internet]. 2012 [acesso em 2016 nov 22];20(2):1-8. Disponível em: http://www.redalyc.org/articulo.oa?i $\mathrm{d}=281422733010$

17. Neves ET, Andres B, Silveira A, Arrué AM. A rede social de cuidados de uma criança com necessidade especial de saúde. Rev eletrônica enferm [Internet]. 2013 [acesso em 2016 nov 